\title{
Prophylaxis of medial compartment gonarthrosis in varus knee - current state of knowledge
}

\author{
Anna Fryzowicz ${ }^{1}$, Lechosław B. Dworak², Paweł Koczewski ${ }^{3}$
}

${ }^{1}$ Chair of Biomechanics, University School of Physical Education, Poznan, Poland ${ }^{2}$ Chair of Bionics, University of Arts, Poznan, Poland ${ }^{3}$ Department of Pediatric Orthopedics and Traumatology, Poznan University of Medical Sciences, Poznan, Poland

Submitted: 1 July 2015

Accepted: 8 October 2015

Arch Med Sci 2018; 14, 2: 454-459

DOI: 10.5114/aoms.2016.57961

Copyright @ 2016 Termedia \& Banach

\author{
Corresponding author: \\ Anna Fryzowicz \\ Chair of Biomechanics \\ University School \\ of Physical Education \\ 27/39 Królowej Jadwigi St \\ 61-871 Poznan, Poland \\ Phone: +48 663870715 \\ E-mail: fryzowicz.anna@ \\ gmail.com
}

\begin{abstract}
The progression of gonarthrosis results in reduction of physical activity. One of the factors that increase the risk of osteoarthrosis may be joint overload related to the malalignment of the mechanical axis of the lower extremity. The medial compartment (MC) of the knee is particularly susceptible to overload due to the external knee adduction moment (EKAM). Varus knee malalignment contributes to increased EKAM and thus results in increased MC loading. The purpose of this study is to present methods described in current literature aimed at reducing the disproportion in the distribution of loads on articular surfaces of medial and lateral knee compartments in people with varus knee malalignment. Methods have been divided into non-surgical (gait training, physiotherapy, and orthopedic supplies such as valgus braces, lateral wedge insoles, walking poles) and surgical ones (corrective osteotomy).
\end{abstract}

Key words: osteoarthrosis, osteotomy, prevention, insoles, physiotherapy.

\section{Introduction}

The articular surfaces of the knee joint are among the most frequent locations where degenerative changes occur. The progression of gonarthrosis and the related pain as well as knee range of movement (ROM) limitation result in significant reduction in physical activity and work capacity. One of the risk factors for the degenerative disease may be the mechanical overload of the joint due to lower extremity (LE) malalignment [1].

In normal conditions, the mechanical axis of the LE - the line connecting the center of the femoral head with the center of the ankle joint - goes through the center of the knee joint. In a standing position this results in equal distribution of loads between both compartments of the tibiofemoral joint - lateral (LC) and medial (MC) [2]. During gait this balance is disturbed, and around $70 \%$ of the load is borne by the MC due to medial orientation of the ground reaction force (GRF) vector to the knee joint center [3]. The main biomechanical indirect indicator of MC loading during gait is the external knee adduction moment (EKAM) [3]. The EKAM is a product of the GRF in the frontal plane (sum of vector components: vertical and lateral-medial GRF) and the length of the orthogonal 
moment arm running toward the center of the knee joint, termed the frontal plane lever arm [4] (Figure $1 \mathrm{~A}$ ). The EKAM and GRF have two peaks (early and late) during the stance phase, whereas the lever arm length is relatively constant [4]. The first peak EKAM is typically the largest [4].

In recent years the relationship between EKAM and MC loading has been confirmed by studies on patients with instrumented knee implants installed, which enabled in vivo measurements of the load acting on tibial articular surfaces [5-8].

In varus knees the mechanical axis runs medially to the center of the knee joint. This causes the transition of the majority of the load onto the MC already during standing [2]. During the stance phase the increased EKAM results mainly from increased length of the lever arm (Figure 1 B) and indicates $M C$ overload $[4,9,10]$. This results in a higher risk of onset $[11,12]$ as well as further progression [13-15] of medial gonarthrosis in varus knee malalignment.

Some researchers also use EKAM impulse [1618], which provides information on cumulative knee load through the stance phase [16], as indirect $M C$ loading measure. Chang et al. confirmed that increased EKAM impulse contributes to me- dial gonarthrosis progression [15]. According to Walter et al., who found that increased external knee flexion moment (EKFM) may contribute to MC loading increase [8], EKFM has also been used as an indirect $M C$ loading measure $[16,18,19]$. Since EKFM was not correlated with likelihood of medial gonarthrosis progression [15], we did not take it into account in this review.

The purpose of this study is to present methods described in current literature that are aimed at reducing EKAM and EKAM impulse and thereby the MC loading in patients who are at risk of early medial gonarthrosis related to varus knee malalignment.

\section{Non-invasive actions that modify MC loading}

Medial compartment loading may be decreased non-invasively with gait modifications or orthopedic supplies. These methods are aimed at reducing EKAM (GRF or lever arm) or EKAM impulse.

\section{Gait training}

There are some characteristics of gait that reduce $M C$ loading. The first consists in increasing the foot progression angle (FPA), i.e. placing
A

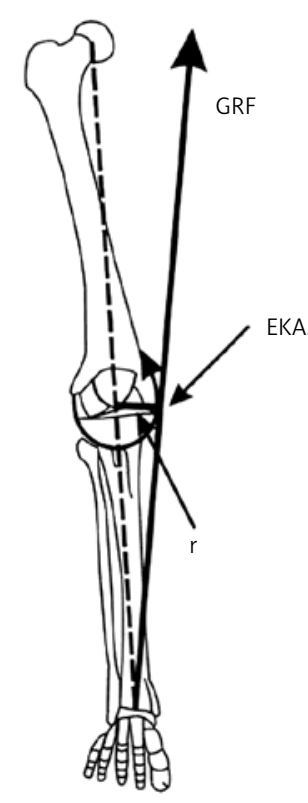

Neutrally aligned knee
B

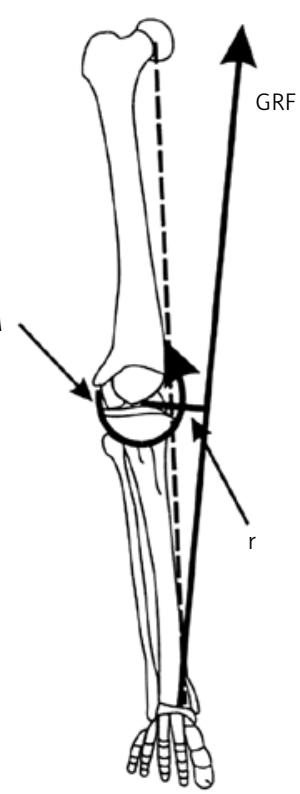

Increased EKAM in varus knee
C

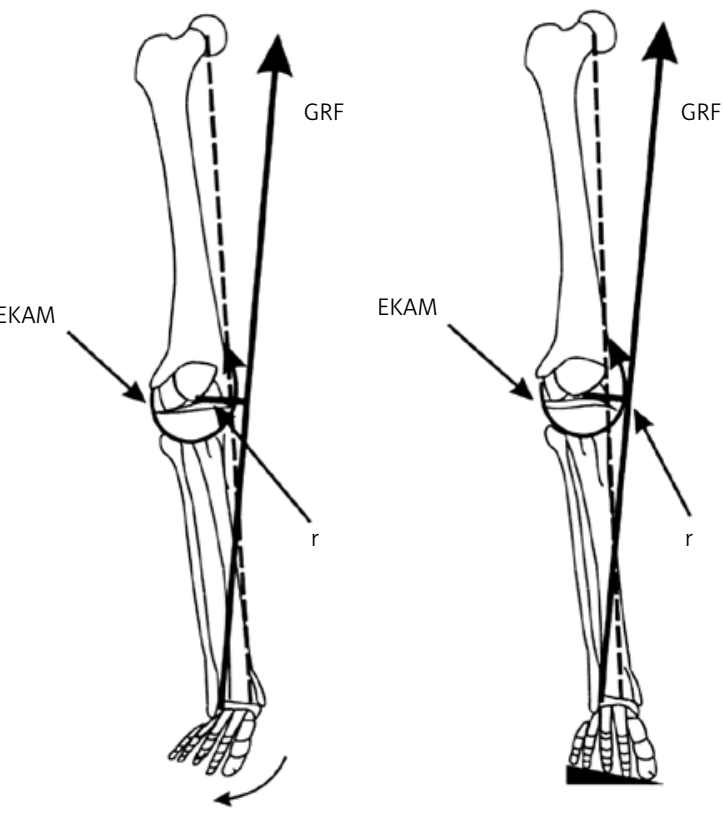

Gait with increased FPA decrease EKAM in varus knee
D

Gait with lateral wedge insoles decrease EKAM in varus knee

Figure 1. A - EKAM in neutrally aligned knee during the stance phase of the gait cycle; mechanical axis of the LE goes through the knee joint center; B - knee varus malalignment results in increased length of the frontal plane lever arm and increased EKAM during the stance phase; mechanical axis of the LE goes medially to the knee joint center; C - increased FPA in varus knee shifts GRF vector laterally, reducing frontal plane lever arm and consequently reducing EKAM during the stance phase; D - lateral wedge insoles in varus knee shift GRF vector laterally, reducing frontal plane lever arm and consequently reducing EKAM during the stance phase (fig. based on [10]) GRF - ground reaction force, EKAM - external knee adduction moment, $r$-frontal plane lever arm, dotted line - mechanical axis of the $L E$. 
feet externally to the forward progression line (out-toeing) (Figure $1 \mathrm{C}$ ). This mechanism shifts laterally the center of pressure (COP), and consequently the GRF vector runs more laterally, closer to the knee joint center, reducing the frontal plane lever arm [19], with no GRF increase [16]. Out-toeing reduces the second peak EKAM and EKAM impulse both in patients with varus knees and medial gonarthrosis $[18,19]$ and in healthy persons [16]. Although out-toeing increases the first peak EKAM, it contributes to slowing down the medial gonarthrosis progression [20]. By contrast, other research indicated the gait with decreased FPA (in-toeing) to be more effective for individuals with medial gonarthrosis [21]. In-toeing shifts the COP laterally and the knee joint center medially [21]. As a result, the frontal plane lever arm is reduced, with no GRF increase, and the first peak EKAM decreases [16, 18]. These observations, however, have not been supported by long-term studies yet, and Simic et al. found that in-toeing besides the positive effect also may increase the second peak EKAM [18].

Increased internal hip abduction moment during the stance phase also protects against medial gonarthrosis progression [22]. Stronger ipsilateral hip abductors help in maintaining the trunk over the loaded LE during the stance phase therefore the GRF vector runs more laterally, closer to the knee joint center. As a result, the frontal plane lever arm is reduced [22]. Other studies focused on the influence of lateral trunk lean over the stance $L E[16,17,23]$ support this observation. This gait modification results in shifting the center of body mass laterally; therefore the frontal plane GRF vector runs closer to the knee joint center and the lever arm is reduced [23]. Leaning the trunk laterally over the stance LE results in a first and second peak EKAM as well as EKAM impulse decrease in patients with medial gonarthrosis [17] and in healthy persons [16].

Medial thrust, which is a combination of slight knee flexion and internal hip rotation during the stance phase, reduces $M C$ loading in persons with

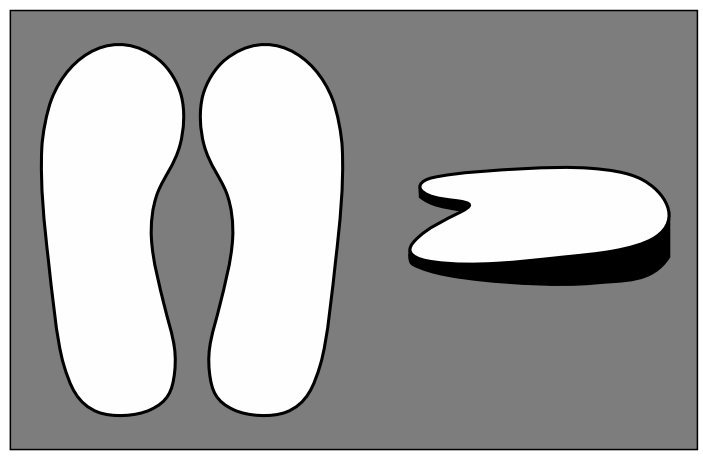

Figure 2. Example of orthopedic lateral wedge insoles, with elevation under the lateral edge of the sole (fig. based on [35]) proper alignment $[16,24]$. However, there are no papers that report its influence on MC loading in varus knees.

\section{Orthopedic equipment and supplies}

Lateral wedge insoles (Figure 2) reduces the EKAM by shifting the COP laterally and thus reducing the frontal plane lever arm [25-27] (Figure $1 \mathrm{D}$ ). Lateral wedge insoles with additional support under the longitudinal arch of the foot improve EKAM reduction and foot function in healthy persons [28]. Soft neutral insoles also reduces MC loads in healthy persons by reducing the vertical component of GRF while walking [29].

On the other hand, patients with medial gonarthrosis respond differently to lateral wedge insoles. Although insoles may contribute to EKAM decrease [27, 30], they do not necessarily alleviate the symptoms, slow down the medial gonarthrosis progression or improve joint functionality [31]. This may arise from already persistent structural changes in the foot joints that are meant to compensate for the varus knee malalignment [32]. Maly et al. reported no change in EKAM after using lateral wedge insoles [33].

Another medical product, valgus braces, produce constant valgus moment at the knee, which results in slight MC separation and pain relief [34]. The effectiveness of valgus braces in relieving the $M C$ pain is comparable to the surgical treatment - high tibial osteotomy (HTO) [34]. Valgus braces are reported to be more effective in reducing EKAM than lateral wedge insoles [35]. Although valgus braces improve functionality and reduce knee pain, they may not be tolerated for a long period [36] due to e.g. skin irritation or impracticality $[34,36]$.

Next, walking poles decreased MC loading in one person with force-measuring knee replacement installed, by transferring some of the GRF through the contralateral walking pole [24]. On the other hand, research on a group of patients with medial gonarthrosis and varus knee malalignment showed contrary results [37]. Although walking poles reduced GRF, at the same time frontal plane lever arm length increased and consequently EKAM increased [37].

\section{Physiotherapy}

There is a lack of thorough cohort studies in the field of physiotherapy effectiveness in varus knee malalignment decrease. A case study of a 16-year-old boy reported a reduction of varus knee malalignment from $7 \mathrm{~cm}$ to $3 \mathrm{~cm}$ of intercondylar distance after 23 months of therapy with the Postural Reconstruction method [38]. This therapy is based on neuromuscular facilitation/inhibition 
mechanisms with no direct manipulation on painful areas [38]. The effect continued after 3 years of observation [38].

Generally, manual therapy is considered mainly as an additional help in restoring proper LE alignment with high tibial osteotomy (HTO) [39-43] or directly before and after arthroplasty [44]. However, by acting on the soft tissue one may slow down the onset of medial gonarthrosis or reduce the symptoms. Bennel et al. showed that exercises aimed at strengthening hip adductors and abductors in a group of patients with varus knees and medial gonarthrosis improved knee functioning and reduced pain although no EKAM decrease was observed [45].

It is not clear whether strengthening the quadriceps in patients with gonarthrosis and LE axis malalignment is appropriate. Stronger quadriceps in persons with knee malalignment and decreased knee stability is related to higher risk of gonarthritis progression [46], and quadriceps strength is not correlated with EKAM regardless of the degree of varus knee malalignment [47]. On the other hand, Segal et al. found that stronger knee extensors in a group of people over 50 years old reduce symptoms related to gonarthrosis (pain, knee stiffness) [48]. What is more, a 12-week training program aimed at strengthening knee joint extensors in patients with medial gonarthrosis contributed to reduced pain, although only in those with a normal LE axis [49].

\section{Surgical treatment}

Surgical treatment of varus knee malalignment aims first of all at restoring proper distribution of loads on articular surfaces of the tibiofemoral joint by correcting the LE axis in the frontal plane. In children this effect may be achieved by asymmetric epiphysiodesis [50]. In active young adults a corrective HTO is performed (Figure 3) [39, 50]. It allows one to delay or avoid unicondylar or total knee arthroplasty [50], which is required in endstage gonarthrosis [51].

The effect of EKAM decrease after HTO is obvious. This procedure restores LE alignment from varus (Figure $1 \mathrm{~B}$ ) to normal (Figure $1 \mathrm{~A}$ ). There are only a few papers focused on the biomechanics of this procedure [40-43], and they show that after HTO in adults with varus knee malalignment and medial gonarthrosis there can be observed: EKAM decrease [40-43] that continues even 2 years after the surgery [40], improved knee joint stability [41], reduced cocontraction of the vastus medialis and the medial head of the gastrocnemius muscle [41], which is associated with an MC loading decrease [42], and knee ROM normalization [43].

On the other hand, there are many reports that confirm the clinical efficacy of this treatment [39,
52-55]. There are different opinions on the shape and the level of HTO, the choice of the stabilization device, the amount of correction or hypercorrection and indications for this surgery. These variables depend on the deformation magnitude and gonarthrosis severity. HTO clinical effectiveness is measured by lessened pain, improved stability and, as a result, total knee replacement postponement.

The HTO shape and level may depend not only on the LE alignment but also on the condition of knee ligaments. In order to improve the lateral knee joint stability, the osteotomy should be localized above the insertion of the tibial collateral ligament insertion to increase its tension. However, there are reports suggesting that there is no predominance of any HTO surgery [52] or osteosynthesis [53] technique. Fujisawa et al. suggested hypercorrection because of the possibility of lost cartilage regeneration after mechanical axis translation towards a less destroyed knee joint compartment [54]. Jakob and Murphy [55] defined the amount of hypercorrection for different degrees of knee joint space narrowing. However, there are also reports that contradict the possibility of cartilage regeneration after hypercorrection [56].

\section{Synthesis of current knowledge and conclusions}

On the basis of this review of the literature, it may be deduced that: in adults, proper exercise, manual therapy or orthopedic supplies may only reduce the $M C$ loading (delay the onset of medial gonarthrosis). Realigning the LE axis in adults may be achieved by performing corrective osteotomy (medial gonarthrosis prevention). Since methods described in this article may contribute to the MC
A

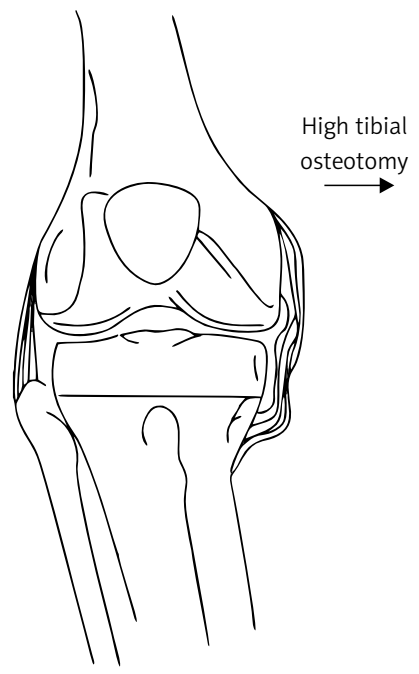

B

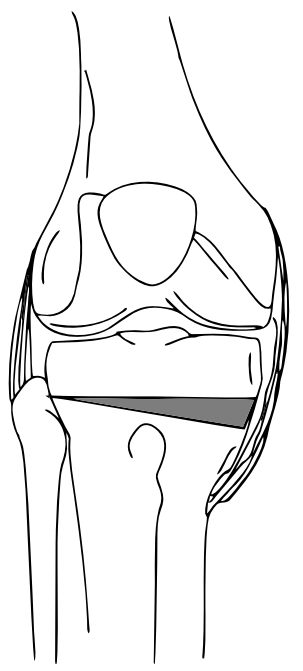

Figure 3. Example of high tibial osteotomy used for varus knee malalignment correction: A - varus knee malalignment; B - corrected knee alignment after high tibial osteotomy (fig. based on [39]) 
loading decrease, slow down the progression of medial gonarthrosis and as a result delay the necessity of knee arthroplasty, physicians and physiotherapists should be aware of them when treating varus knee malalignment in adults. There are some contradictory reports on the effectiveness of various nonsurgical procedures used to reduce the $M C$ loading in varus knee. Therefore certain exercises or orthopedic supplies should be prescribed for a particular patient with caution.

\section{Acknowledgments}

This study was financed by a grant for "Development of Young Scientists" from the Polish Ministry of Science and Higher Education for the Faculty of Physical Education, Sport and Rehabilitation, University School of Physical Education in Poznan and a grant of the Polish Ministry of Science and Higher Education for the statutory activity of the Chair of Bionics, University of Arts in Poznan - Project No. AiW/1/2015.

The authors thank Krzysztof Kmiecik, MEng, for preparing the figures.

\section{Conflict of interest}

The authors declare no conflict of interest.

\section{References}

1. Wierusz-Kozłowska M, Markuszewski J. Choroba zwyrodnieniowa stawów. In: Wiktora Degi ortopedia i rehabilitacja. Vol. 2. Marciniak W, Szulc A (eds.). PZWL, Warsaw 2003; 274-89.

2. Johnson F, Leitl S, Waugh W. The distribution of load across the knee. A comparison of static and dynamic measurements. J Bone Joint Surg 1980; 62-B: 346-9.

3. Andriacchi TP. Dynamics of knee malalignment. Orthop Clin North Am 1994; 25: 395-403.

4. Hunt MA, Birmingham TB, Giffin J R, Jenkyn TR. Associations among knee adduction moment, frontal plane ground reaction force, and lever arm during walking in patients with knee osteoarthritis. J Biomech 2006; 39: 2213-20.

5. Kutzner I, Trepczynski A, Heller MO, Bergmann G. Knee adduction moment and medial contact force - facts about their correlation during gait. Plos One 2013; 8: e81036.

6. Meyer AJ, D'Lima DD, Besier TF, Lloyd DG, Colwell Jr. CW, Fregly BJ. Are external knee load and EMG measures accurate indicators of internal knee contact forces during gait? J Orthop Res 2013; 31: 921-9.

7. Zhao D, Banks SA, Mitchell KH, D'Lima DD, Colwell Jr. CW, Fregly BJ. Correlation between the knee adduction torque and medial contact force for a variety of gait patterns. J Orthop Res 2007; 25: 789-97.

8. Walter JP, D'Lima DD, Colwell Jr CW, Fregly BJ. Decreased knee adduction moment does not guarantee decreased medial contact force during gait. J Orthop Res 2010; 28: 1348-54.

9. Foroughi N, Smith RM, Lange AK, Baker MK, Singh MAF, Vanwanseele B. Dynamic alignment and its association with knee adduction moment in medial knee osteoarthritis. Knee 2010; 17: 210-6.
10. Mündermann A, Dyrby CO, Andriacchi TP. A comparison of measuring mechanical axis alignment using three-dimensional position capture with skin markers and radiographic measurements in patients with bilateral medial compartment knee osteoarthritis. Knee 2008; 15: 480-5.

11. Brouwer GM, van Tol AW, Bergink AP, et al. Association between valgus and varus alignment and the development and progression of radiographic osteoarthritis of the knee. Arthritis Rheum 2007; 56: 1204-11.

12. Sharma L, Chmiel JS, Almagor O, et al. The role of varus and valgus alignment in the initial development of knee cartilage damage by MRI: the MOST study. Ann Rheum Dis 2013; 72: 235-40.

13. Eckstein F, Wirth W, Hudelmaier M, et al. Patterns of femorotibial cartilage loss in knees with neutral, varus, and valgus alignment. Arthritis Rheum 2008; 59: 1563-70.

14. Miyazaki T, Wada M, Kawahara H, Sato M, Baba H, Shimada S. Dynamic load at baseline can predict radiographic disease progression in medial compartment knee osteoarthritis. Ann Rheum Dis 2002; 61: 617-22.

15. Chang AH, Moisio KC, Chmiel JS, et al. External knee adduction moment and flexion moments during gait and medial tibiofemoral disease progression in knee osteoarthritis. Osteoarthr Cartilage 2015; 23: 1099-106.

16. Gerbrands TA, Pisters MF, Vanwanseele B. Individual selection of gait retraining strategies is essential to optimally reduce medial knee load during gait. Clin Biomech 2014; 29: 828-34.

17. Simic M, Hunt MA, Bennell KL, Hinman RS, Wrigley TV. Trunk lean gait modification and knee joint load in people with medial knee osteoarthritis: the effect of varying trunk lean angles. Arthrit Care Res 2012; 64: 1545-53.

18. Simic M, Wrigley TV, Hinman RS, Hunt MA, Bennell KL. Altering foot progression angle in people with medial knee osteoarthritis: the effect of varying toe-in and toeout angles are mediated by pain and malalignment. Osteoarthr Cartilage 2013; 21: 1272-80.

19. Jenkyn TR, Hunt MA, Jones IC, Giffin JR, Birmingham TB. Toe-out gait in patients with knee osteoarthritis partially transforms external knee adduction moment into flexion moment during early stance phase of gait: a tri-planar kinetic mechanism. J Biomech 2008; 4: 27683.

20. Chang A, Hurwitz D, Dunlop D, et al. The relationship between toe-out angle during gait and progression of medial tibiofemoral osteoarthritis. Ann Rheum Dis 2007; 66: $1271-5$

21. Shull PB, Shultz R, Silder A, et al. Toe-in gait reduces the first peak knee adduction moment in patients with medial compartment knee osteoarthritis. J Biomech 2013; 46: $122-8$

22. Chang A, Hayes K, Dunlop D, et al. Hip abduction moment and protection against medial tibiofemoral osteoarthritis progression. Arthritis Rheum 2005; 52: 3515-9.

23. Hunt MA, Birmingham TB, Bryant D, et al. Lateral trunk lean explains variation in dynamic knee joint load in patients with medial compartment knee osteoarthritis. Osteoarthr Cartilage 2008; 16: 591-9.

24. Fregly BJ, D'Lima DD, Colwell Jr CW. Effective gait patterns for offloading the medial compartment of the knee. J Orthop Res 2009; 27: 1016-21.

25. Crenshaw SJ, Pollo FE, Calton EF. Effects of lateral-wedged insoles on kinetics at the knee. Clin Orthop Relat Res 2000; 375: 185-92.

26. Haim A, Rozen N, Dekel S, Halperin N, Wolf A. Control of knee coronal plane moment via modulation of center of 
pressure: a prospective gait analysis study. J Biomech 2008; 41: 3010-6.

27. Kakihana W, Akai M, Nakazawa K, Takashima T, Naito K, Torii S. Effects of laterally wedged insoles on knee and subtalar joint moments. Arch Phys Med Rehabil 2005; 86: 1465-71.

28. Nakajima K, Kakihana W, Nakagawa T, et al. Addition of an arch support improves the biomechanical effect of a laterally wedged insole. J Biomech 2009; 29: 208-13.

29. Creaby MW, May K, Bennell KL. Insole effects on impact loading during walking. Ergonomics 2011; 54: 665-71.

30. Hinman RS, Bowles KA, Bennell KL. Laterally wedged insoles in knee osteoarthritis: do biomechanical effects decline after one month of wear? BMC Musculoskeletal Disorders 2009; 10: 146.

31. Bennell KL, Bowles KA, Payne C, et al. Lateral wedge insoles for medial knee osteoarthritis: 12 month randomised controlled trial. BMJ 2011; 342: d2912.

32. Levinger P, Menz HB, Morrow AD, Feller JA, Bartlett JR, Bergman NR. Foot kinematics in people with medial compartment knee osteoarthritis. Rheumatology (Oxford) 2012; 51: 2191-8.

33. Maly MR, Culham EG, Costigan PA. Static and dynamic biomechanics of foot orthoses in people with medial compartment knee osteoarthritis. Clin Biomech 2002; 17: 603-10.

34. Minzlaff P, Saier T, Brucker PU, Haller B, Imhoff AB, Hinterwimmer $\mathrm{S}$. Valgus bracing in symptomatic varus malalignment for testing the expectable "unloading effect" following valgus high tibial osteotomy. Knee Surg Sports Traumatol Arthrosc 2015; 23: 1964-70.

35. Pagani CHF, Hinrichs M, Brüggemann G. Kinetic and kinematic changes with the use of valgus knee brace and lateral wedge insoles in patients with medial knee osteoarthritis. J Orthop Res 2011; 30: 1125-32.

36. Brouwer RW, van Raaij TM, Verhaar JA, Coene LN, Bierma-Zeinstra SM. Brace treatment for osteoarthritis of the knee: a prospective randomized multi-centre trial. Osteoarthr Cartilage 2006; 14: 777-83.

37. Bechard DJ, Birmingham TB, Zecevic AA, et al. The effect of walking poles on the knee adduction moment in patients with varus gonarthrosis. Osteoarthr Cartilage 2012; 20: 1500-6.

38. Destieux C, Gaudreault N, Isner-Horobeti ME, Vautravers P. Use of postural reconstruction ${ }^{\circledR}$ physiotherapy to treat an adolescent with asymmetric bilateral genu varum and idiopathic scoliosis. Ann Phys Rehabil Med 2013; 56: 312-26.

39. Paley D, Maar DC, Herzenberg JE. New concepts in high tibial osteotomy for medial compartment osteoarthritis. Orthop Clin North Am 1994; 25: 483-98.

40. Birmingham TB, Giffin JR, Chesworth BM, et al. Medial opening wedge high tibial osteotomy: a prospective cohort study of gait, radiographic, and patient-reported outcomes. Arthritis Rheum 2009; 61: 648-57.

41. Ramsey DK, Snyder-Mackler L, Lewek M, Newcomb W, Rudolph KS. Effect of anatomic realignment on muscle function during gait in patients with medial compartment knee osteoarthritis. Arthritis Rheum 2007; 57: 389-97.

42. Lewek MD, Rudolph KS, Snyder-Mackler L. Control of frontal plane knee laxity during gait in patients with medial compartment knee OA. Osteoarthr Cartilage 2004; 12: 745-51.

43. Lind M, McClelland J, Wittwe JE, Whitehead TS, Feller JA, Webster KE. Gait analysis of walking before and after medial opening wedge high tibial osteotomy. Knee Surg Sports Traumatol Arthrosc 2013; 21: 74-81.
44. Czyżewska A, Glinkowski WM, Walesiak K, Krawczak K, Cabaj D, Górecki A. Effects of preoperative physiotherapy in hip osteoarthritis patients awaiting total hip replacement. Arch Med Sci 2014; 10: 985-91.

45. Bennel KL, Hunt MA, Wrigley TV, et al. Hip strengthening reduces symptoms but not knee load in people with medial knee osteoarthritis and varus malalignment: a randomised controlled trial. Osteoarthr Cartilage 2010; 18: 621-8.

46. Sharma L, Dunlop D, Cahue S, Song J, Hayes KW. Quadriceps strength and osteoarthritis progression in malaligned and lax knees. Ann Intern Med 2003; 138: 613-9.

47. Lim B, Kemp G, Metcalf B, et al. The association of quadriceps strength with the knee adduction moment in medial knee osteoarthritis. Arthritis Rheum 2009; 61: 451-8.

48. Segal NA, Torner JC, Felson D, et al. Effect of thigh strength in incident radiographic and symptomatic knee osteoarthritis in a longitudinal cohort. Arthritis Rheum 2009; 61: 1210-7.

49. Lim B, Hinman RS, Wrigley TV, Sharma L, Bennell KL. Does knee malalignment mediate the effects of quadriceps strengthening on knee adduction moment, pain, and function in medial knee ostaoarthritis? A randomized controlled trial. Arthritis Rheum 2008; 59: 943-51.

50. Koczewski P. Zaburzenia osi kończyn dolnych i zasady ich korekcji. In: Wiktora Degi ortopedia i rehabilitacja. Vol. 2. Marciniak W, Szulc A (eds.). PZWL, Warsaw 2003; 465-95.

51. Seng CS, Ho DC, Chong HC, et al. Outcomes and survivorship of unicondylar knee arthroplasty in patients with severe deformity. Knee Surg Sports Traumatol Arthrosc 2017; 25: 639-44.

52. Brouwer RW, Huizinga MR, Duivenvoorden T, et al. Osteotomy for treating knee osteoarthritis. Cochrane Database Syst Rev 2014, doi: 10.1002/14651858.CD004019. pub4.

53. Khurana D, Sankhala SS, Malik M, Shekhawat V, Rathore DS. Comparative study of high tibial osteotomy using dynamic axial fixator and locked low-profile plate in medial osteoarthritis of knee. Eur J Orthop Surg Traumatol 2015; 25: 763-73.

54. Fujisawa Y, Masuhara K, Shiomi S. The effect of high tibial osteotomy on osteoarthritis of the knee. An arthroscopic study of 54 knee joints. Orthop Clin North Am 1979; 8: 585-608.

55. Jakob RP, Murphy SB. Tibial osteotomy for varus gonarthrosis: indication, planning, and operative technique. Instr Course Lect 1992; 41: 87-93.

56. Tsukada S, Wakui M. Is overcorrection preferable for repair of degenerated articular cartilage after open-wedge high tibial osteotomy? Knee Surg Sports Traumatol Arthrosc 2017; 25: 785-92. 